\title{
EPMA Studies on Reactions Between Ti and Al during Spark Plasma Sintering
}

\author{
Yu Sun ${ }^{1}$, Kaustubh Kulkani ${ }^{2}$, Mark Aindow ${ }^{1}$, Anil Sachdev ${ }^{3}$ and Enrique Lavernia ${ }^{4}$ \\ ${ }^{1}$ Department of Materials Science and Engineering, and Institute of Materials Science, University of \\ Connecticut, Storrs, CT 06269, USA \\ ${ }^{2}$ Department of Materials Science and Engineering, Indian Institute of Technology, Kanpur 208016, \\ U.P., India \\ ${ }^{3 .}$ Chemical Sciences and Materials Systems Lab, GM Global R\&D Center, Warren, MI 48090-9055, \\ USA \\ ${ }^{4}$ Department of Chemical Engineering and Materials Science, University of California, Davis, CA \\ 95616-5294, USA
}

Spark plasma sintering (SPS) is a promising techniques for the production of near-net-shape TiAl components for structural applications [1]. Previous studies on SPS of Ti-Al composites have revealed a two-step reaction mechanism for the formation of $\gamma$-TiAl. Results show that first, all of the Al was consumed to form $\mathrm{TiAl}_{3}$ via reaction $1\left(\alpha-\mathrm{Ti}+3 \mathrm{Al}=\mathrm{TiAl}_{3}\right)$ at a temperature below the melting point of $\mathrm{Al}$; and second, $\gamma$-TiAl was formed by further interdiffusion between $\mathrm{Al}_{3} \mathrm{Ti}$ and the remaining $\mathrm{Ti}$ at higher temperatures via reaction $2\left(2 \mathrm{Ti}+\mathrm{TiAl}_{3}=3 \mathrm{TiAl}\right)[2,3]$. However, a review of published studies reveals that the diffusive reaction mechanism between $\mathrm{Ti}$ and $\mathrm{Al}_{3} \mathrm{Ti}$ under electric field remains poorly understood. The objective of the present work was to identify the phases formed by the diffusive reaction between $\mathrm{Ti}$ and $\mathrm{TiAl}_{3}$, as well as their formation sequence, and thereby provide insight into the reaction mechanisms that govern the formation of $\gamma$-TiAl from $\mathrm{Ti}$ and $\mathrm{TiAl}_{3}$.

A cryomilled $\mathrm{Ti}-\mathrm{Al}$ powder blend with a chemical composition of $\mathrm{Ti}_{53} \mathrm{Al}_{47}$ was SPS consolidated at $600^{\circ} \mathrm{C}$ for $15 \mathrm{~min}$. Under these conditions the $\mathrm{TiAl}_{3}$ diffusion layers were fully developed. The assintered compacts were further SPS consolidated at $1250^{\circ} \mathrm{C}$ for $5 \mathrm{~min}$. The diffusion layers disappeared, and lamellar phase colonies developed along with regions of high Al concentration (dark contrast on Fig 1a). Representative backscattered SEM micrographs are shown in Fig 1.

To reveal the details of the intermediate reactions, compacts consolidated by SPS at $600^{\circ} \mathrm{C}$ for $15 \mathrm{~min}$ were further SPS processed at $900^{\circ} \mathrm{C}$ for 5 and $10 \mathrm{~min}$. A typical SEM micrograph from the latter sample is shown in Fig 2a. The interdiffusion between $\mathrm{TiAl}_{3}$ and $\mathrm{Ti}$ caused development of multiple intermetallic layers between them. XRD data obtained from these samples (e.g. Fig. 2e) revealed the presence of $\mathrm{TiAl}, \mathrm{TiAl}_{2}$ and $\mathrm{Ti}_{3} \mathrm{Al}$ in addition to the reactants $\mathrm{Ti}$ and $\mathrm{TiAl}_{3}$. This phase sequence is in accordance with the Ti-Al binary phase diagram, which also shows the existence of metastable $\mathrm{TiAl}_{2}$ phase. EPMA X-Ray mapping and quantitative analysis were done at $15 \mathrm{keV}$ and $10 \mathrm{nA}$ beam conditions on the area shown in Fig 2a. The Ti and Al maps are shown in Figs $2 b$ and 2c, respectively. An X-Ray line scan was acquired along the position shown by the dark bar in Fig $2 \mathrm{a}$, and the results are shown in Fig $2 \mathrm{~d}$. As per the phase diagram, the metastable $\mathrm{TiAl}_{2}$ phase appears up to $1215^{\circ} \mathrm{C}$. This implies that the SPS processing temperature for the complete formation of $\gamma$-TiAl should be higher than $1215^{\circ} \mathrm{C}$.

\section{Acknowledgments}

The authors would like to thank the management of General Motors for supporting this research. EJL would also like to thank the support from National Science Foundation with a grant number NSF DMR1210437. 


\section{References:}

[1] J. E. Garay, Annual Review of Materials Research 40 (2010) 445.

[2] G. P. Chaudhari and V. L. Acoff, Intermetallics 18 (2010) 472.

[3] J. G. Luo and V. L. Acoff, Materials Science and Engineering a-Structural Materials Properties Microstructure and Processing 379 (2004) 164.
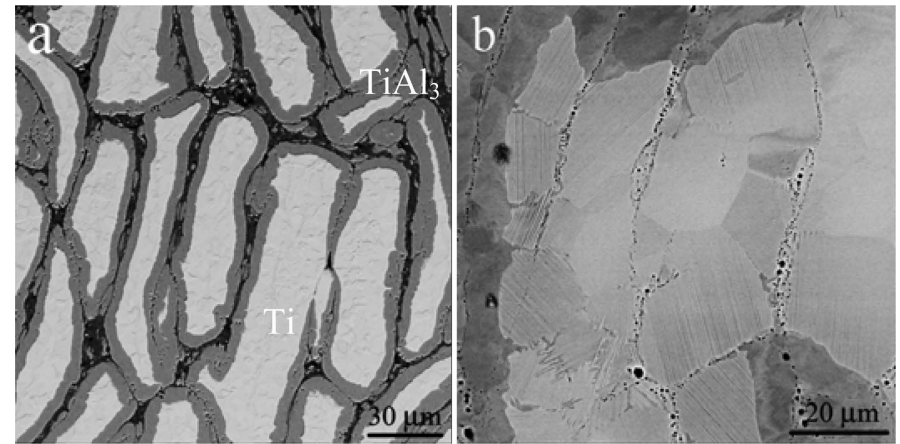

Figure 1: Backscattered SEM micrograph of cryomilled Ti-Al powder blend compact after SPS at $600^{\circ} \mathrm{C}$ for $15 \mathrm{~min}(\mathrm{a})$ and SPS at $600^{\circ} \mathrm{C}$ for $15 \mathrm{~min}$ followed by SPS at $1250^{\circ} \mathrm{C}$ for $5 \mathrm{~min}$ (b) on Ti-Al powder compacts.
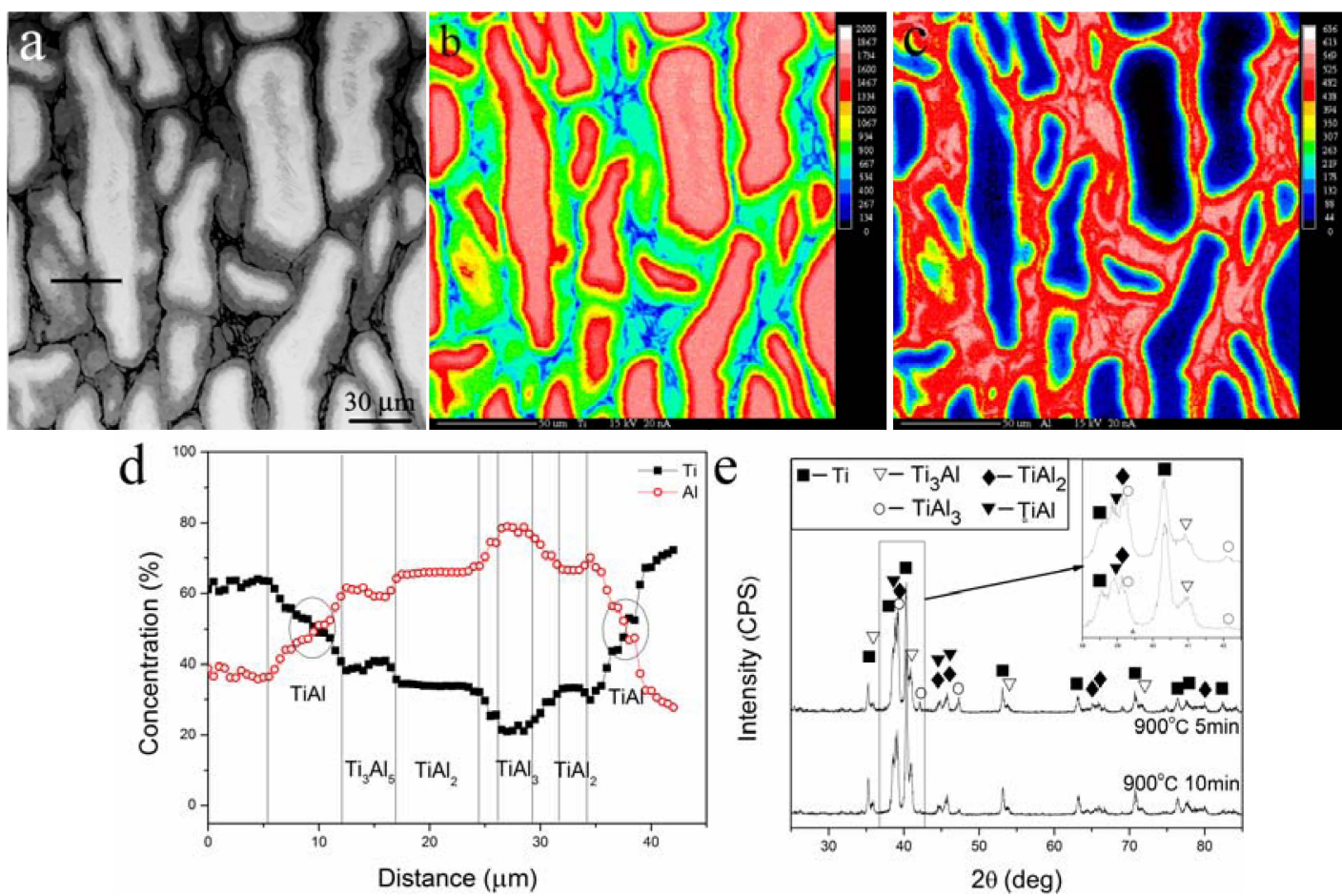

Figure 2. Cryomilled Ti-Al powder blend compact after SPS at $600 \mathrm{C}$ for $15 \mathrm{~min}$ followed by SPS at $900^{\circ} \mathrm{C}$ for $10 \mathrm{~min}$, Backscattered SEM micrograph (a), EPMA X-Ray mapping of the Ti (b) and Al (c) $\mathrm{X}$-Ray line scan across interfaces (d). XRD patterns of the Ti-Al compact SPS at $600^{\circ} \mathrm{C}$ for 15 min followed by SPS at $900^{\circ} \mathrm{C}$ for 5 and $10 \mathrm{~min}$. 